\section{Importância dos ácidos graxos essenciais e os efeitos dos ácidos graxos trans do leite materno para o desenvolvimento fetal e neonatal}

\author{
The importance of essential fatty acids and the \\ effect of trans fatty acids in human milk on \\ fetal and neonatal development
}

\author{
${ }^{1}$ Departamento de Ciencias \\ Fisiológicas, Universidade do \\ Estado do Rio de Janeiro, Rio \\ de Janeiro, Brasil. \\ 2 Instituto de Medicina \\ Social, Universidade do \\ Estado do Rio de Janeiro, Rio \\ de Janeiro, Brasil. \\ 3 Centro de Ciências da \\ Saúde, Universidade Federal \\ do Rio de Janeiro, Rio de \\ Janeiro, Brasil. \\ Correspondência \\ M. G. T. Carmo \\ Instituto de Nutrição Josué \\ de Castro, Centro de Ciências \\ da Saúde, Universidade \\ Federal do Rio de Janeiro. \\ Av. Brigadeiro Trompowski \\ $s / n$, Bloco J, 2o andar, \\ Rio de Janeiro, $R J$ \\ 21941-590, Brasil. \\ tcarmo@editema.com.br
}

\begin{abstract}
Breastfeeding has a major impact on public health, since human breast milk is the best food for infants up to six months of age. The lipid fraction in human milk is the main source of energy for the infant and supplies essential nutrients such as fat-soluble vitamins and polyunsaturated fatty acids (PUFA). Essential fatty acids (EFA), specifically linoleic acid (LA, 18:2n-6) and $\alpha$-linolenic acid (ALA, 18:3n-3), are precursors of long-chain polyunsaturated fatty acids (LC-PUFA), including docosahexaenoic (DHA) and arachidonic (ARA) acids. Quality of lipids in secreted milk is precisely related to maternal ingestion. LC-PUFAs protect against allergy and infection and are important for visual and cognitive development in infancy. Industrial food processing has introduced the trans fatty acids (TFA) among the nutrients available to the population. TFA can interfere with the metabolism of essential fatty acids by decreasing LC-PUFA synthesis. It is thus important to raise population awareness on the importance of adequate PUFA consumption and reduced TFA intake during prenatal and postnatal development.
\end{abstract}

Essential Fatty Acids; Trans Fatty Acids; Human Milk; Fetal Development

\author{
Sandra Manzato Barboza Tinoco ${ }^{1}$ \\ Rosely Sichieri 2 \\ Anibal Sanchez Moura 1 \\ Flávia da Silva Santos 3 \\ Maria das Graças Tavares do Carmo ${ }^{3}$
}

\section{A importância dos ácidos graxos no leite materno}

Nas últimas décadas, especial atenção tem sido dada à composição e aos aspectos fisiológicos da fração lipídica do leite humano 1,2. A média do conteúdo de gordura no leite materno é de $3,8 \mathrm{~g} / 100 \mathrm{ml}$, porém este valor varia amplamente. O lipídio está presente no leite materno na forma de glóbulos de gordura, os quais são sintetizados pelas células alveolares mamárias. Esta síntese é estimulada pelo esvaziamento do seio materno durante a amamentação, e a secreção de prolactina no lóbulo anterior da glândula pituitária 3 .

A fração lipídica do leite materno representa a maior fonte de energia para crianças amamentadas, contribuindo com 40 a 55\% do total de energia ingerida, e provê nutrientes essenciais tais como vitaminas lipossolúveis e ácidos graxos poliinsaturados (AGPI), incluindo ácido linoléico da série n-6 (LA, 18:2n-6) e $\alpha$-linolênico da série n-3 (ALA, 18:3n-3) ${ }^{4}$.

Os ácidos graxos que compõem os lipídios do leite são em grande número e pertencentes a dois grupos: o dos ácidos graxos saturados (sem ligações duplas) e o dos ácidos graxos insaturados (com uma ou mais ligações duplas) 5. Os ácidos graxos de cadeia curta, de cadeia média e de cadeia longa saturados e monoinsaturados podem ser sintetizados no organismo, porém os AGPI, notadamente o linoléico e $\alpha$-linolênico, por não serem sintetizados pelo organismo constituem- 
se em ácidos graxos essenciais (AGE) 6. Tais ácidos são elementos estruturais necessários à síntese de lipídios de tecidos, e têm um papel importante na regulação de vários processos metabólicos, de transporte e excreção. A carência de AGE na alimentação dos mamíferos (especialmente do homem) conduz a alterações no crescimento, na pele, imunológicas, neurológicas, e sérios transtornos comportamentais 6 .

A qualidade dos lipídios da dieta materna tem influência direta no perfil de ácidos graxos do leite secretado 7 . Uma dieta rica em carboidratos irá favorecer a síntese endógena dos ácidos graxos de cadeia curta e média e uma dieta rica em ácidos graxos poliinsaturados vai determinar maiores níveis destes no leite secretado 8 .

Por outro lado, crianças que recebem leite contendo baixo teor de lipídios tendem a mamar mais freqüentemente e por maiores períodos de tempo, causando um aumento no volume do leite. Há também uma correlação positiva entre o ganho de peso durante a gestação e o conteúdo de lipídios do leite 9 . Dessa forma, a relação entre a ingestão dietética materna de lipídios, a composição corporal adiposa materna e a concentração de lipídios no leite é de crucial importância na nutrição infantil durante o aleitamento.

\section{A importância dos ácidos graxos poliinsaturados de cadeia longa para o crescimento e o desenvolvimento}

Os ácidos graxos poliinsaturados de cadeia longa (AGPI-CL) no leite materno podem originar-se da ingestão dietética materna, dos estoques maternos e da síntese endógena a partir de seus precursores com 18 carbonos, no fígado, glândula mamária e outros tecidos 1 .

A dieta materna influencia o conteúdo no leite dos ácidos eicosapentaenóico (EPA, 20:5n-3), docosahexaenóico (DHA, 22:6n-3) e araquidônico (ARA, 20:4n-6), que pode aumentar pelo consumo de peixe, leite, carne e ovos 1,10.

Os AGPI-CL de origem dietética são absorvidos, reesterificados em triacilgliceróis, entram na circulação na forma de quilomicrons, e são rapidamente transferidos para a glândula mamária pela ação da lipase lipoprotéica, sendo em seguida transferidos para o leite materno. Os triacilgliceróis hepáticos também são transportados (como VLDL) do fígado para a glândula mamária e liberados deste tecido por ação da lipase lipoprotéica 1. Durante a lactação, a atividade da lipase lipoprotéica diminui no tecido adiposo e aumenta no tecido mamário, indicando um aumento da captação de ácidos graxos para este tecido 8 .
Devido à intensa lipólise que ocorre durante a lactação, os AGPI dos triacilgliceróis armazenados no tecido adiposo são liberados e podem ser transportados na circulação como ácidos graxos não esterificados ligados à albumina, podendo ser direcionados para a célula alveolar mamária 1 .

Vários estudos têm demonstrado que o DHA do fosfolipídio do plasma materno é significativamente e positivamente correlacionado com a ingestão de DHA 11, e com a quantidade de DHA no leite materno ${ }^{12}$. Altas quantidades de DHA no leite materno proporcionam altas quantidades de DHA no plasma e nos eritrócitos de crianças amamentadas no seio 12,13 .

Embora a dieta materna represente um papel importante como fonte de ácidos graxos para o leite, os resultados dos estudos com isótopos estáveis demonstram que a proporção de AGPI no leite não tem como principal origem a dieta materna 1,14,15.

Koletzko et al. 1 estudaram seis mulheres lactantes que receberam três vezes uma dose oral $\mathrm{de} 1 \mathrm{mg} / \mathrm{kg}$ de peso corporal de LA na 2ạ , 6a e 12a semanas de lactação, respectivamente. Nesse estudo, eles observaram que $30 \%$ do total de LA no leite foram transferidos diretamente da dieta e $70 \%$ dos depósitos maternos.

Demmelmari et al. 14 observaram que de 3 a $25 \%$ e até cerca $3 \%$ dos conteúdos de 20:3 n- 6 e 20:4 n-6 no leite, respectivamente, foram provenientes do 18:2 n-6 ingerido. Esses resultados demonstram que a contribuição dos ácidos graxos essenciais para a secreção de AGPI-CL para o leite é pequena, e que os estoques corporais maternos contribuem significativamente para a produção dos lipídios no leite humano. Dessa forma, isso poderia indicar que o hábito dietético da mulher, por influenciar na composição dos estoques corporais, pode ser um marcador relevante para a composição de gordura do leite. Os AGPI-CL podem também ser originados a partir da metabolização dos ácidos graxos essenciais: ácido linoléico (LA, 18:2n-6) e ácido $\alpha$-linolênico (ALA, 18:3n-3), os quais são precursores dos AGPI-CL com 20 e 22 átomos de carbono, incluindo os ácidos araquidônico (ARA, 20:4n-6), docosahexaenóico (DHA, 22:6n-3) e eicosapentaenóico (EPA, 20:5n-3) 1,2. Os ácidos ARA e DHA são formados na maioria dos tecidos do organismo por uma série de reações alternadas de dessaturação (adição de duplas ligações) e alongação (adição de duas unidades de carbono) 1 (Figura 1). Os ácidos LA e ALA não podem ser sintetizados nas células mamárias pela ausência das enzimas $\Delta 12$ e 15 , necessárias para a inserção da dupla ligação na posição n-6 ou n-3 da cadeia de carbono do ácido graxo, sendo, portanto, 
Figura 1

Biossíntese de ácidos graxos poliinsaturados.
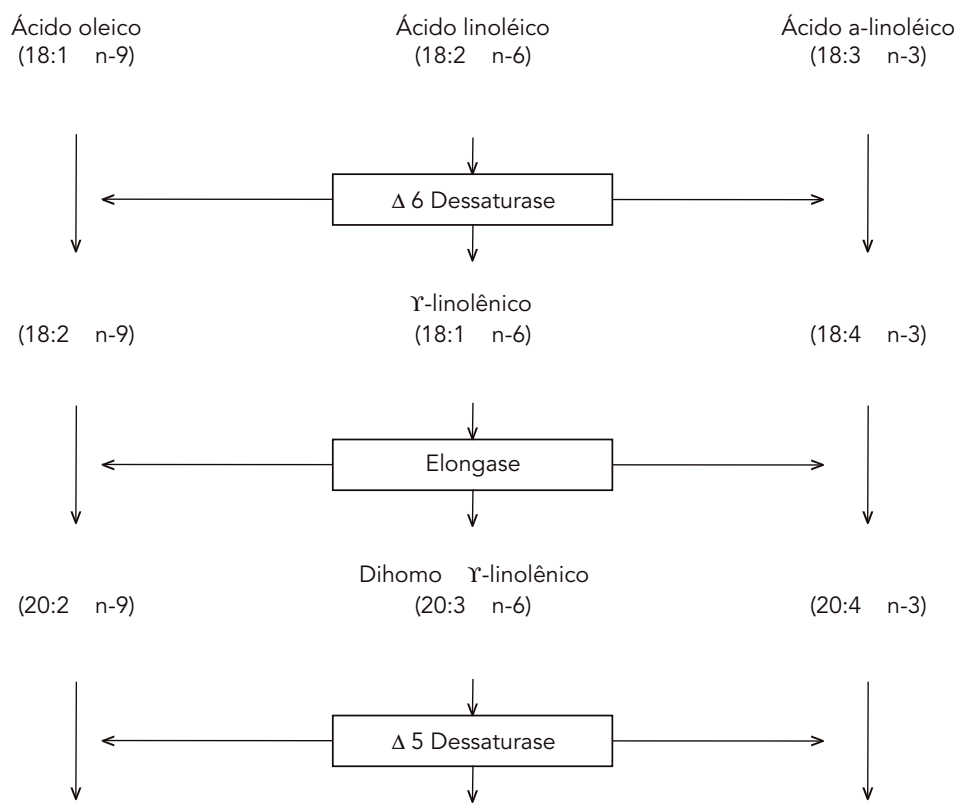

$(20: 3 \quad n-9)$
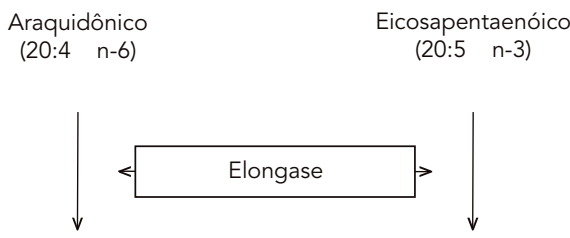

$(20: 4 \quad n-6)$

$(20: 5 \quad n-3)$

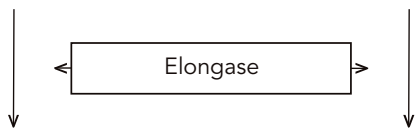

$(24: 4 \quad n-6)$

$(24: 5 \quad n-3)$

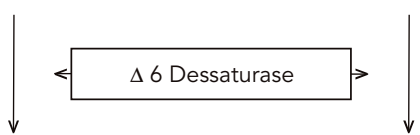

$(24: 5 n-6)$

$(24: 6 \quad n-3)$

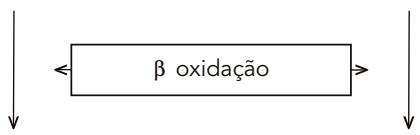

Docosapentaenóico $(22: 5 n-6)$

Docosahexaenóico $(22: 6 \quad n-3)$

Fonte: Uauy \& Castillo 2. 
considerados nutrientes dietéticos essenciais 4 (Figura 1). Antes do nascimento, todos os ácidos graxos n-6 e n-3 acumulados pelo feto provêm da circulação materna através da transferência placentária, e depois do nascimento originamse do leite materno quando a amamentação materna for exclusiva 4,16. Essa dependência é demonstrada por estudos que indicam forte correlação positiva materno-fetal para todos os ácidos graxos essenciais e seus AGPI-CL 4,17,18. A habilidade da placenta em extrair esses ácidos graxos da circulação materna e transferi-los para o feto é de crucial importância 10. Esses ácidos graxos para serem transportados através da membrana dos microvilos do sinciciotrofoblasto da placenta, necessitam estar na forma não esterificada (ácidos graxos não esterificados - AGNE) 19. Na circulação materna, os AGNE podem ser provenientes da hidrólise dos triacilgliceróis das lipoproteínas pela lipase lipoprotéica placentária, e/ou a partir dos ácidos graxos originados da hidrólise dos triacilgliceróis pela lipase hormônio sensível do tecido adiposo materno 20. Através desse mecanismo, os ácidos graxos são transferidos para o compartimento fetal resultando no enriquecimento de determinados ácidos graxos na circulação fetal que irá depender em grande parte da composição dos ácidos graxos existentes na circulação materna 20 .

De fato, as concentrações de DHA e ARA são maiores no feto que nos fosfolipídios do plasma materno, enquanto seus precursores (LA e ALA) possuem concentrações mais baixas 4,21 . O fato da transferência placentária ser seletivamente maior para o ARA e DHA do que para outros AGPI, determina concentrações sangüíneas fetais mais elevadas desses AGPI-CL por várias semanas após o nascimento da criança 22. Isso é importante devido ao efeito positivo que esses ácidos graxos representam no crescimento fetal, principalmente para crianças nascidas prematuras, e no desenvolvimento do sistema nervoso central 10,16,21.

Os lipídios do cérebro são ricos em AGPI-CL n-3 e n-6, e estes desempenham papel fundamental no crescimento neuronal, transdução de sinais e excitabilidade das membranas neurais, e na expressão de genes que regulam a diferenciação celular e o crescimento ${ }^{23}$. De fato, o DHA além de exercer efeito positivo no crescimento infantil, é o AGPI com maior presença nos segmentos da retina (cones e bastonetes) 4. Aproximadamente $10 \%$ do peso do cérebro e $50 \%$ do peso seco são formados por lipídio, sendo metade fosfolipídio. Os fosfolipídios da massa cinzenta do cérebro contêm grandes proporções de DHA e ARA 4. Altas concentrações de DHA na retina, e de DHA e ARA na massa cinzenta do cérebro sugerem que estes ácidos graxos têm importante função no processo visual e neural 4,13,24.

Portanto, a ingestão dietética adequada desses AGPI-CL ou de seus precursores durante o período perinatal é essencial para o crescimento fetal e neonatal, para o desenvolvimento e para as funções neurológica, comportamental e de aprendizagem 16. Além disso, a nutrição intrauterina pode influenciar no risco do desenvolvimento de doenças crônicas na fase adulta 25 , sugerindo que o padrão de nutrição no início da vida pode "marcar" (metabolic imprinting) o indivíduo, conduzindo, portanto, a uma "programação” metabólica. Isso enfatiza a importância da adequação dietética de AGPI essenciais durante a gravidez, a lactação e a infância. A importância fisiológica dos ácidos graxos n-3 no desenvolvimento neural e visual da criança tem sido estudada intensamente nos últimos anos. Innis et al. ${ }^{26}$, em estudo com registro de 83 crianças que receberam aleitamento materno exclusivo por pelo menos três meses, analisaram as células vermelhas do sangue e as concentrações de ácidos graxos no plasma nas crianças com dois meses de idade, a acuidade visual com 2, 4, 6 e 12 meses, desenvolvimento da linguagem com nove meses e índice de desenvolvimento mental e psicomotor com 6 e 12 meses. Eles relataram correlação positiva do DHA com medidas de acuidade visual e progressão no desenvolvimento da linguagem, que foi determinada pela habilidade da criança em distinguir sílabas de sua língua nativa de uma linguagem não familiar.

Estudos experimentais têm demonstrado que a depleção de DHA no desenvolvimento da retina e do cérebro resulta em diminuição da função visual com anormalidades no eletroretinograma, déficits de aprendizado e alterações no metabolismo de dopamina e serotonina 27. Outros estudos clínicos demonstram que o DHA aumenta a acuidade visual, a habilidade motora e o desenvolvimento da linguagem em crianças prematuras 13,28 .

Recentemente, vários estudos experimentais têm revelado que a deficiência de ácidos graxos $\mathrm{n}$-3 altera o metabolismo da dopamina e serotonina no cérebro de roedores 29. Particular interesse tem sido dado ao sistema dopaminérgico, devido à importante função da dopamina no desenvolvimento cognitivo no início da infância, como modulador de atenção e motivação, e em processos visuais 16,30 .

Segundo Das 31, receptores de insulina nas células do cérebro têm função cognitiva, incluindo aprendizado e memória. Sugere-se que uma das funções dos AGPI-CL no cérebro pode ser a manutenção de um adequado número de receptores de insulina nas membranas celulares neu- 
ronais, conseqüentemente modulando a função cognitiva.

Já o ácido graxo araquidônico é essencial para o crescimento normal, e é criticamente importante por sua função de sinalização e divisão celular, e como precursor dos eicosanóides da série 2 e leucotrienos da série 3 , que também desempenham função na transmissão sináptica 21 .

A qualidade e a quantidade da ingestão de gordura na dieta materna, em especial a proporção entre o consumo dos AGPI n-3 e n-6, têm sido tema de discussão em relação à prevalência de atopia. Kankaanpaa et al. ${ }^{32}$, investigando a possível influência entre dieta materna, desenvolvimento de atopias e AGPI no leite humano de mães alérgicas e não-alérgicas, concluíram que proporções elevadas de AGPI n-6 ou proporções reduzidas de AGPI regulatórios (ácido $\gamma$-linolênico e AGPI n-3) podem ser um fator de risco para o desenvolvimento de doenças atópicas.

$\mathrm{Na}$ atualidade, sabe-se que dois subtipos de células, TH1 e TH2, participam na atividade global do sistema imunitário. As células TH1 são responsáveis pela imunidade celular e segregam citocinas pró-inflamatórias, tais como a interleucina (IL) 2, o fator de necrose tumoral alfa (TNF$\alpha$ ) e o interferon-gama (IFN- $\gamma$ ). Pelo contrário, as células TH2 produzem IL-4, IL-5, IL-10, IL-13, regulando as respostas imunitárias humorais, modulando a atividade das células TH1, e diminuindo a inflamação local ${ }^{33}$.

Os AGPI n-3 e n-6 modulam a geração de células TH1 e TH2, a produção de suas citocinas e a proliferação de células, portanto podem servir como moléculas endógenas anti-inflamatórias 34 . Os AGPI-CL presentes no leite materno, especialmente o EPA e o DHA, suprimem a síntese e a liberação de TNF- $\alpha$, portanto podem servir como reguladores endógenos negativos de inflamação 35,36. Além disso, os AGPI-CL diminuem a expressão de proteínas $B c l$ - $x \mathrm{~L}$ e $\mathrm{Bcl}$-2, identificadas como antiapoptóticas, sugerindo que estes ácidos graxos têm habilidade de prevenir e suprimir doenças auto-imunes 33 . Quantidades adequadas de AGPI-CL durante o período perinatal protegem contra atopias, asma, doenças autoimunes, diabete mellitus dos tipos I e II, hipertensão, doenças cardíacas, síndrome metabólica $\mathrm{X}$, linfomas, leucemia e outros tipos de câncer, esquizofrenia, depressão e outras doenças 4 . Essa proteção é resultado da ação moduladora dos AGPI-CL na expressão de genes relacionados à resposta imune 33 .

Portanto, a presença dos AGPI-CL no leite ajuda no desenvolvimento do sistema imune da criança, atuando na produção de células $\mathrm{T}$ 37. Isso é particularmente importante, já que a função do linfócitoTépouco desenvolvida no nascimento 38.
Crianças que nasceram com algum grau de imaturidade imunológica passam a ser suscetíveis a infecções e a respostas dietéticas anormais (alergias) ${ }^{39}$. A redução da habilidade da criança em responder à resposta proliferativa quando expostos a mitógenos (agentes ativantes) pode ser resultado de baixo número de células T CD45RO+ ou limitada habilidade em produzir citocinas, particularmente interleucina (IL)-4 e Il-10 38.

Todas essas evidências sugerem, portanto, que os AGPI-CL devem estar disponíveis em quantidades adequadas durante o período crítico de crescimento e desenvolvimento em vários tecidos e órgãos para prevenção de doenças na vida adulta. A quantidade de ácidos graxos poliinsaturados que cada lactente recebe por dia através do aleitamento varia conforme a dieta materna e o estágio da lactação. Gibson \& Makrides 40 relatam valores de 200mg de ARA e $\leq 100 \mathrm{mg}$ de DHA/dia, quantidades estas que poderiam ser suficientes para atender às necessidades do crescimento $\mathrm{e}$ do desenvolvimento.

\section{Ácidos graxos trans e desenvolvimento infantil}

Nos últimos anos, investigações sobre o efeito nutricional e biológico dos ácidos graxos trans (AGT) têm aumentado extensamente devido à importância dos lipídios no crescimento e no desenvolvimento infantil 41,42. Os AGT são ácidos graxos insaturados com pelo menos uma dupla ligação na configuração trans, ou seja, dois átomos de hidrogênio do carbono adjacente em direções opostas no ponto da dupla ligação (Figura 2).

Figura 2

Configuração cis e trans de uma dupla ligação.
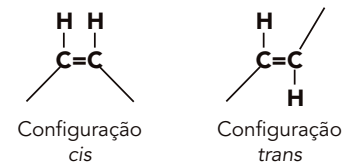

Os AGT podem ser encontrados em alimentos como margarinas sólidas ou cremosas, massas, recheios de biscoitos, formulações de bases para sopas e cremes, coberturas para adesão de especiarias e açúcares, sorvetes, pães, batata fri- 
ta, pastelarias, bolos, tortas e massas, entre outros alimentos industrializados 43 . No Brasil são desconhecidos os teores de ácidos graxos trans nos alimentos industrializados, prejudicando a orientação em relação ao seu consumo. Em 1999, a Food and Drug Administration (FDA) 44 sugeriu que a quantidade de ácidos graxos trans fosse incluída nos rótulos de produtos. No Brasil, a Agência Nacional de Vigilância Sanitária (ANVISA) 45 já determinou a obrigatoriedade da declaração do conteúdo de ácidos graxos trans em rótulos de produtos industrializados a partir de julho de 2006.

Os estudos realizados sobre o transporte dos AGT através da placenta apresentam resultados contraditórios 46 . As observações mais recentes indicam que esses ácidos graxos são transferidos da mãe para o feto $21,47,48$.

No estudo de Elias \& Innis 21 realizado com mulheres na 35a semana de gestação, observouse nos triacilgliceróis plasmáticos proporções médias de $4 \%$ de AGT nas mães e 2,9\% de AGT nos recém-nascidos, sugerindo que de alguma forma a placenta apresenta algum grau de discriminação contra esses ácidos graxos. No entanto, a quantidade de AGT detectado nos fosfolipídios fetais foi correlacionada com os valores encontrados nos fosfolipídeos maternos, indicando portanto, que a dieta materna determina em grande parte a composição dos ácidos graxos nos fosfolipídeos fetais.

Em estudo recente de revisão, Orozco ${ }^{49}$ relata que os AGT são transferidos da placenta ao feto e incorporados aos tecidos fetais, sendo esta incorporação relativamente baixa no cérebro. Estudos experimentais também observaram baixa incorporação de trans nos tecidos cerebrais 50 . Esses resultados indicam que nesse período de rápido desenvolvimento, o cérebro é mais preservado que os outros órgãos com respeito à acumulação de trans.

Relato recente na literatura aponta que os AGT podem afetar o crescimento e o desenvolvimento de diferentes maneiras: (1) através da inibição das vias de dessaturação do LA e ALA para ARA e DHA, respectivamente; (2) metabolismo dos ácidos graxos trans monoenóicos (18:1 $t$ ) para ácidos graxos isoméricos não usuais de cadeia mais longa $n-6$ e $n-3$, os quais podem alterar as funções das membranas e as vias de síntese de eicosanóides; (3) baixa ingestão de AGE devido à destruição do LA e ALA durante a hidrogenação parcial dos óleos vegetais, acarretando nos alimentos industrializados, diminuição dos teores de ácidos graxos essenciais como LA e principalmente de ALA 51

A hipótese de que dietas com AGT podem inibir a biossíntese de AGPI-CL com 20 e 22 átomos de carbono e, conseqüentemente, afetar o desenvolvimento infantil, é defendida por autores que demonstram correlação inversa dos AGT no plasma com ácidos graxos poliinsaturados $n-3$ e n-6 em crianças 21 . Tecidos infantis incorporam AGT do leite materno, aumentando os níveis de ácido linoléico, e relativamente diminuem os níveis dos ácidos ARA e DHA; sugerindo efeito inibitório do AGT sobre a atividade das enzimas $\Delta$-6 e $\Delta$-5 ácido graxo dessaturases, prejudicando a alongação e o sistema de dessaturação dos ácidos graxos essenciais 52,53 .

Sugere-se, ainda, que os trans afetam o crescimento intra-uterino por inibição da biossíntese dos AGPI-CL, sendo esta hipótese sustentada por estudos que demonstram que os AGT têm sido inversamente correlacionados com o peso no nascimento de crianças prematuras e bebês a termo 53,54,55. Além disso, o efeito dos trans sobre o retardo do crescimento se sustenta no importante efeito do DHA no processo de crescimento da criança, que é associado positivamente com o peso e a estatura no nascimento e com a circunferência do crânio 56. Pesquisas na Holanda indicam que a presença de AGT no cordão umbilical está associada com quantidades proporcionalmente menores de ácidos graxos essenciais, reduzido peso ao nascer e menor perímetro cefálico 57 .

A conversão dos ácidos graxos essenciais a AGPI-CL pode ser especialmente difícil para fetos e bebês prematuros que dependem do suprimento materno destes ácidos, não apenas para o crescimento fetal como também para o desenvolvimento e a maturação do cérebro, a manutenção do sistema vascular e a síntese de eicosanóides 46,52,53.

Apesar de todos esses estudos, ainda não é conhecido se a exposição do AGT em etapas precoces da vida, ou seja, durante a infância, acarreta conseqüências negativas para a criança. Os poucos estudos existentes são ainda inconclusi$\operatorname{vos} 46,47$. O concenso atual é, portanto, moderar o consumo de AGT durante o desenvolvimento, devido a seus potenciais efeitos adversos 49,51.

\section{Ácidos graxos trans no leite materno}

Os trans maternos podem ser transferidos para a criança também através da amamentação. O conteúdo de AGT é variável no leite materno, refletindo a ingestão dietética materna 42,58 . Depende principalmente do consumo recente de margarinas, gordura vegetal hidrogenada e produtos industrializados 42 . Devido à preocupação sobre a exposição da criança aos AGT, diferentes 
países têm analisado as concentrações destes ácidos no leite materno.

Em geral, os AGT compreendem 2 a $5 \%$ do total de ácidos graxos do leite materno ${ }^{46}$, porém amplas variações aparecem quando se analisam diferentes populações e diferentes hábitos dietéticos, variando de $7,2 \%$ no Canadá 59 a 1,9\% na França 60.

Estudos experimentais confirmam uma relação dose-resposta direta entre a ingestão de AGT e a incorporação dos mesmos no leite materno, sendo transferidos para os filhotes por meio da lactação, vindo a aparecer no plasma e na aorta 58 .

Chen et al. 59, em um estudo epidemiológico, encontraram correlação inversa entre AGT e os níveis de ácidos graxos essenciais no leite materno de mães canadenses, sugerindo que o aumento de AGT pode ocorrer à custa dos ácidos graxos essenciais, já que produtos dietéticos com grande quantidade de AGT usualmente contêm menos ácidos graxos essenciais.

Spear et al. 61 estudaram a composição de ácidos graxos no leite de uma mesma mulher durante aleitamentos consecutivos. A dieta materna e o ganho de peso (18 e 22,7kg, respectivamente) foram semelhantes durante a primeira e a segunda gravidez. A primeira criança nasceu com $5,2 \mathrm{~kg}$ e recebeu aleitamento exclusivo até o terceiro mês de vida, e o segundo bebê nasceu um ano depois, com 4,3kg e recebeu leite materno exclusivo até o segundo mês de vida. A dieta materna não variou durante os dois períodos de lactação. Spear et al. 61 observaram pequenas mudanças durante a lactação. Esses autores concluíram que quando o mesmo padrão de dieta é consumido, observamse pequenas variações na composição de ácidos graxos do leite em aleitamentos consecutivos.

Em estudo recente, avaliamos as variações e associações dos ácidos graxos do leite materno (AGE, AGPI-CL e AGT) com o crescimento de crianças prematuras 62 . Os AGT foram encontrados em todas as amostras de leite materno, po- rém $77 \%$ apresentaram valores de trans inferiores a $3 \%$. O conteúdo total de AGE e o total de AGPI n-6 foram inversamente correlacionados com os AGT, tanto no colostro quanto no leite maduro. Além disso, encontramos correlação positiva entre os níveis de ácido araquidônico (ARA, 20:4n-6) no leite maduro e a estatura das crianças $(\mathrm{r}=0,32, \mathrm{p}=0,05)$.

Pelo que foi exposto acima, pode-se perceber que o consumo materno de ácidos graxos trans é um fator de interferência no estado nutricional no tocante aos ácidos graxos essenciais e AGPI-CL. Conseqüentemente, o teor de ácidos graxos n-3 e n-6 na criança no nascimento é um importante determinante nas concentrações de ARA e DHA no organismo do neonato, e a exposição aos AGT derivados da dieta materna pode ser um fator que interfere no crescimento e no desenvolvimento da criança 21 .

Conclui-se, portanto, que a qualidade dos lipídios dietéticos ofertados através do leite materno durante os primeiros meses de vida, período criticamente importante, pode ser determinante no crescimento e no desenvolvimento infantil, assim como na resposta imunológica da criança contra agentes infecciosos e na prevenção de doenças na vida adulta. Dessa forma, recomenda-se que a dieta da mulher gestante e lactante contenha suficientes quantidades de AGPI essenciais e seus metabólitos de cadeia mais longa, para atender tanto os requerimentos maternos quanto os fetais e do neonato. Se a ingestão dos AGPI essenciais é insuficiente para atender aos requerimentos fisiológicos, os estoques corporais podem ser utilizados como um suprimento adicional. Considerando que o início do desenvolvimento pós-natal é a fase onde o crescimento celular encontra-se mais ativo, maior atenção deve ser dada ao consumo de AGT durante a lactação, devido aos seus efeitos negativos no metabolismo dos ácidos graxos essenciais. 


\section{Resumo}

A prática da amamentação tem grande impacto do ponto de vista da saúde pública, pois o leite materno é o melhor alimento a ser oferecido até o sexto mês de vida da criança. A fração lipídica do leite representa a maior fonte de energia para crianças e fornece nutrientes essenciais, tais como vitaminas lipossolúveis e ácidos graxos poliinsaturados (AGPI). Os ácidos graxos essenciais (AGE) linoléico (LA, 18:2n-6) e $\alpha$-linolênico (ALA, 18:3n-3) são precursores dos ácidos graxos poliinsaturados de cadeia longa (AGPI-CL), incluindo os ácidos docosahexaenóico (DHA) e araquidônico (ARA). A qualidade dos lipídios no leite secretado está diretamente relacionada com a ingestão materna. Os AGPI-CL são importantes na proteção contra alergia e infecções, no processo visual e no desenvolvimento cognitivo na infância. O processamento industrial de alimentos introduziu os ácidos graxos trans (AGT) entre os nutrientes disponíveis à população. Os AGT podem interferir no metabolismo dos AGE, diminuindo a sintese de DHA e ARA. Portanto, nos parece relevante esclarecer a população sobre a importância de um aporte adequado de AGPI e reduzido de AGT durante o período de desenvolvimento pré e pós-natal.

Ácidos Graxos Essenciais; Ácidos Graxos Trans; Leite Humano; Desenvolvimento Fetal

\section{Referências}

1. Koletzko B, Rodriguez-Palmero M, Demmelmair H, Fidler N, Jensen R, Sauerwald T. Physiological aspects of human milk lipids. Early Hum Dev 2001; 65 Suppl:S3-18.

2. Uauy R, Castillo C. Lipid requirements of infants: implications for nutrient composition of fortified complementary foods. J Nutr 2003; 133:2962S-72S.

3. McManaman JL, Neville MC. Mammary physiology and milk secretion. Adv Drug Deliv Rev 2003; 55 Suppl 5:629-41.

4. Innis SM. Perinatal biochemistry and physiology of long-chain polyunsaturated fatty acids. J Pediatr 2003; 143(4 Suppl):S1-8.

5. Connor WE. Importance of $n-3$ fatty acids in health and disease. Am J Clin Nutr 2000; 1 (1 Suppl): 171S-5S.

6. Innis SM. Polyunsaturated fatty acids in human milk: an essential role in infant development. Adv Exp Med Biol 2004; 554:27-43.

7. Cunha J, Macedo CTH, Ito MK. Influences of maternal dietary intake and suckling on breast milk lipid and fatty acid composition in low-income women from Brasilia, Brazil. Early Hum Dev 2005; 81:303-11.

\section{Colaboradores}

S. M. B. Tinoco participou de todos os estágios da confecção deste artigo, desde a revisão da literatura até a redação e a revisão final do original. R. Sichieri e A. S. Moura colaboraram na concepção e na leitura do original. F. S. Santos participou na revisão da literatura e na redação do original. M. G. T. Carmo contribuiu na concepção, na redação e na revisão do original.

\section{Agradecimentos}

Ao Conselho Nacional de Desenvolvimento Científico e Tecnológico e à Fundação Universitária José Bonifácio.
8. Barber MC, Clegg RA, Travers MT, Vernon RG. Lipid metabolism in the lactating mammary gland. Biochim Biophys Acta 1997; 1347:101-26.

9. Villalpando S, Del Prado M. Interrelation among dietary energy and fat intakes, maternal body fatness, and milk total lipid in humans. J Mammary Gland Biol Neoplasia 1999; 4:285-95.

10. Innis SM. Essential fatty acids transfer and fetal development. Placenta 2005; 26 Suppl A:S70-5.

11. Innis SM, Elias SL. Intakes of essential n-6 and n-3 polyunsaturated fatty acids among pregnant Canadian women. Am J Clin Nutr 2003; 77:473-8.

12. Helland IB, Saugstad OD, Smith L, Saarem K, Solvoll $\mathrm{K}$, Ganes T, et al. Similar effects on infants of $n-3$ and n-6 fatty acids supplementation to pregnant and lactating women. Pediatrics 2001; 108:E82.

13. Jensen CL, Voigt RG, Prager TC, Zou YL, Fraley JK, Rozelle JC, et al. Effects of maternal docosahexaenoic acid intake on visual function and neurodevelopment in breastfed term infants. Am J Clin Nutr 2005; 82:125-32.

14. Demmelmair H, Baumheuer M, Koletzko B, Dokoupil K, Kratl G. Metabolism of U13C-labeled linoleic acid in lactating women. J Lipid Res 1998; 39:1389-96. 
15. Sauerwald TU, Demmelmair H, Fidler N, Koletzko B. Polyunsaturated fatty acid supply with human milk. Physiological aspects and in vivo studies of metabolism. Adv Exp Med Biol 2000; 478:261-70.

16. Fleith M, Clandinin MT. Dietary PUFA for preterm and term infants: review of clinical studies. Crit Rev Food Sci Nutr 2005; 45:205-29.

17. Al MDM, Badart-Smook A, van Houwelingen AC, Hasaart THM, Hornstra G. Fat intake of women during normal pregnancy: relationship with maternal and neonatal essential fatty acids status. J Am Coll Nutr 1996; 15:49-55.

18. Hornstra G. Essential fatty acids in mothers and their neonates. Am J Clin Nutr 2000; 71 (5 Suppl):1262S-9S.

19. Haggarty P. Placental regulation of fatty acid delivery and its effect on fetal growth - a review. Placenta 2002; 23 Suppl A:S28-38.

20. Herrera E. Implications of dietary fatty acids during pregnancy on placental, fetal and postnatal development - a review. Placenta 2002; 23 Suppl A: S9-19.

21. Elias SL, Innis SM. Infant plasma trans, n-6, and n-3 fatty acids and conjugated linoleic acids are related to maternal plasma fatty acids, length of gestation, and birth weight and length. Am J Clin Nutr 2001; 73:807-14.

22. Guesnet P, Pugo-Gunsam P, Maurage C, Pinault M, Giraudeau B, Alessandri JM, et al. Blood lipid concentration of docosahexaenoic and arachidonic acids at birth determine their relative postnatal changes in term infants fed breast milk or formula. Am J Clin Nutr 1999; 70:292-8.

23. Uauy R, Dangour AD. Nutrition in brain development and aging: role of essential fatty acids. Nutr Rev 2006; 64(5 Pt 2):S24-33.

24. Lima MF, Henriques CA, Santos FD, Andrade PMM, Tavares-do-Carmo MG. Ácido graxo ômega 3 docosahexaenóico (DHA: C22:6 n-3) e desenvolvimento neonatal: aspectos relacionados a sua essencialidade e suplementação. Nutrire Rev Soc Bras Aliment Nutr 2004; 28:65-77.

25. Grove KL, Smith MS. Ontogeny of the hypothalamic neuropeptide Y system. Physiol Behav 2003; 79:47-63.

26. Innis SM, Gilley J, Werker J. Are human milk longchain polyunsaturated fatty acids related to visual and neural development in breast-fed term infants? J Pediatr 2001; 139:532-8.

27. De La Presa OS, Innis SM. Docosahexaenoic and arachidonic acid prevent a decrease in dopaminergic and serotoninergic neurotransmitters in frontal cortex caused by a linoleic and alpha-linolenic acid deficient diet in formula-fed piglets. J Nutr 1999; 129:2088-93.

28. O'Connor DL, Hall R, Adamkin D, Auestad N, Castillo M, Connor WE, et al. Growth and development in preterm infants fed long-chain polyunsaturated fatty acids: a prospective randomized controlled trial. Pediatrics 2001; 108:359-71.

29. Zimmer L, Vancassel S, Contagrel S, Breton P, Delmanche S, Guilloteau D, et al. The dopamine mesocorticolimbic pathway is affected by deficiency in $\mathrm{n}-3$ polyunsaturated fatty acids. Am J Clin Nutr 2002; 75:662-777.
30. Basmak H, Yildirim N, Erdinc O, Yurdakul S, Ozdemir G. Effect of levodopa therapy on visual evoked potentials and visual acuity in amblyopia. Ophthalmologica 1999; 213:110-3.

31. Das UN. Long-chain polyunsaturated fatty acids in the growth and development of the brain and memory. Nutrition 2003; 19:62-5.

32. Kankaanpaa P, Nurmela K, Erkkila A, Kalliomaki M, Holmberg-Marttila D, Salminen S, et al. Polyunsaturated fatty acids in maternal diet, breast milk, and serum lipid fatty acids of infants in relation to atopy. Allergy 2001; 56:633-8.

33. Das UN. Perinatal supplementation of long-chain polyunsaturated fatty acids, immune response and adult diseases. Med Sci Monit 2004; 10:HY19-25.

34. Kelley DS. Modulation of human immune and inflammatory responses by dietary fatty acids. Nutrition 2001; 17:669-73.

35. Calder PC. N-3 polyunsaturated fatty acids, inflammation and immunity: pouring oil on troubled waters or another fishy tale? Nutr Res 2001; 21:309-41.

36. De Caterina R, Basta G. N-3 fatty acids and the inflammatory response - biological background. Eur Heart J Suppl 2001; 3:D42-9.

37. Hoppu U, Rinne M, Lampi AM, Isolauri E. Breast milk fatty acid composition is associated with development of atopic dermatitis in the infant. J Pediatr Gastroenterol Nutr 2005; 41:335-8.

38. Field CJ, Clandinin MT, van Aerde JE. Polyunsaturated fatty acids and T-cell function: implications for the neonate. Lipids 2001; 36:1025-32.

39. Rowe J, Heaton T, Kusel M, Suriyaarachchi D, Serralha M, Holt BJ, et al. High IFN-gamma production by CD81 T cells and early sensitization among infants at high risk of atopy. J Allergy Clin Immunol 2004; 113:710-6.

40. Gibson RA, Makrides M. The role of long chain polyunsatured fatty acids (LCAGPI) in neonatal nutrition. Acta Paediatr 1998; 87:1017-22.

41. Larqué E, Zamora S, Gil A. Dietary trans fatty acids affect the essential fatty-acid concentration of rat milk. J Nutr 2000; 130:847-51.

42. Mojska H. Influence of trans fatty acids on infant and fetus development. Acta Microbiol Pol 2003; 52 Suppl:67-74.

43. Semma M. Trans fatty acids: properties, benefits and risks. J Health Sci 2002; 48:7-13.

44. Food and Drug Administration. Food and Drug Administration proposes new rules for trans fatty acids in nutrition labeling, nutrient content clains, and health clains. http://www.access.gpo.gov/su_ docs (acessado em 29/Out/2004).

45. Agência Nacional de Vigilância Sanitária. Resolução RDC n. 360 de 23 de dezembro de 2003. Regulamento técnico sobre rotulagem nutricional de alimentos embalados. Diário Oficial da União 2003; 26 dez.

46. Larqué E, Zamora S, Gil A. Dietary trans fatty acids in early life: a review. Early Hum Dev 2001; 65 Suppl:S31-41.

47. Craig-Schmidt MC. Isomeric fatty acids: evaluating status and implications for maternal and child health. Lipids 2001; 36:997-1006. 
48. Koletzko B, Müller J. Cis- and trans-isomeric fatty acids in plasma lipids of newborn infants and their mothers. Biol Neonate 1990; 57:172-8.

49. Orozco AL. Ácidos grasos trans, cops y lops: evidencia actual de su influencia sobre la salud infantil. Acta Pediatr Esp 2005; 63:22-6.

50. Pettersen J, Opstvedt J. Fatty acid composition of the brain and other organs in the newborn piglet. Lipids 1989; 24:616-24.

51. Innis S. Trans fatty intakes during pregnancy, infancy and early childhood. Atheroscler Suppl 2006; 7:17-20.

52. Carlson SE, Clandinin MT, Cook HW, Emken EA, Filer Jr. LJ. Trans fatty acids: infant and fetal development. Am J Clin Nutr 1997; 66:715S-36S.

53. Koletzko B, Decsi T. Metabolic aspects of trans fatty acids. Clin Nutr 1997; 16:229-37.

54. Decsi T, Koletzko B. Do trans fatty acids impair linoleic acid metabolism in children? Ann Nutr Metab 1995; 39:36-41.

55. Koletzko B. Trans fatty acids may impair biosynthesis of long-chain polyunsaturates and growth in man. Acta Paediatr 1992; 81:302-6.

56. Crawford MA. Placental delivery of arachidonic and docosahexaenoic acids: implications for the lipid nutrition of preterm infants. Am J Clin Nutr 2000; 71(1 Suppl):275S-84S
57. Hornstra G. Essential fatty acids in mothers and their neonates. Am J Clin Nutr 2000; 71:S1262-9.

58. Kummerow FA, Zhou Q, Mahfouz MM, Smiricky MR, Grieshop CM, Schaeffer DJ. Trans fatty acids in hydrogenated fat inhibited the synthesis of the polyunsaturated fatty acids in the phospholipid of arterial cells. Life Sci 2004; 74:2707-23.

59. Chen ZY, Pelletier G, Hollywood R, Ratmayake WMN. Trans fatty acid isomers in Canadian human milk. Lipids 1995; 30:15-21.

60. Chardigny JM, Wolff RL, Mager E, Sebedio JL, Martine L, Juaneda P. Trans mono- and polyunsaturated fatty acids in human milk. Eur J Clin Nutr 1995; 49:523-31.

61. Spear ML, Hamosh M, Bitman J, Spear ML, Wood DL. Milk and blood fatty acid composition during two lactations in the same woman. Am J Clin Nutr 1992; 56:65-70.

62. Tinoco SMB. Variação dos ácidos graxos no leite materno e crescimento de recém-nascidos prematuros [Dissertação de Mestrado]. Rio de Janeiro: Universidade do Estado do Rio de Janeiro; 2005.

Recebido em 17/Out/2005

Versão final reapresentada em 03/Jul/2006 Aprovado em 20/Out/2006 